\title{
Impact of Alcohol Intoxication on Pregnant Albino Wistar Rats; Some Blood Profile and Histopathological Evidence
}

\author{
A. O. Onyemelukwe ${ }^{1 *}$, P. U. Achukwu ${ }^{1}$, N. C. Azubuike ${ }^{1}$, S. I. Ogenyi ${ }^{2}$, \\ O. S. Onwukwe', O. F. Odo ${ }^{3}$ and C. O. Ogu ${ }^{1}$ \\ ${ }^{1}$ Department of Medical Laboratory Science, Faculty of Health Sciences and Technology, \\ University of Nigeria, Enugu Campus, Nigeria. \\ ${ }^{2}$ Department of Medical Laboratory Science, Faculty of Health Sciences and Technology, \\ Nnamdi Azikiwe University, Awka, Nnewi Campus, Nigeria. \\ ${ }^{3}$ Department of Morbid Anatomy, Enugu State University Teaching Hospital, Enugu, Nigeria.
}

Authors' contributions

This work was carried out in collaboration among all authors. Author AOO performed the investigation, collected the data and drafted the initial manuscript. Author PUA conceptualized this study, designed the methodology and supervised the research work. Author NCA performed the statistical analysis and critically reviewed the manuscript. Authors SIO, OSO and OFO assisted in the literature search. Author $\mathrm{COO}$ assisted in data collection. All authors read and approved the final manuscript.

\section{Article Information}

DOI: 10.9734/ARRB/2020/v35i130175

Editor(s):

(1) Dr. Robin Maskey, Internal Medicine, BPKIHS University, Dharan, Nepal.

Reviewers:

(1) Olakunle Olutoye Osinubi, University of Ibadan, Nigeria. (2) Welma Emidio da Silva, Universidade Federal Rural de Pernambuco, Brazil.

(3) T. Leon Stephan Raj, St. Xavier's College, India. Complete Peer review History: http://www.sdiarticle4.com/review-history/54940

Original Research Article

Received 18 December 2019

Accepted 23 February 2020

Published 14 March 2020

\section{ABSTRACT}

Aim: To investigate the effects of alcohol consumption on serum biochemistry and histomorphology of liver, kidneys and uterus of pregnant Albino Wistar rats.

Study Design: An experimental study which lasted for six weeks was conducted in the Animal house of the Department of Physiology, University of Nigeria Enugu Campus.

Methodology: Twenty (20) female albino Wistar rats were used in this study. They were divided into five groups $(n=4)$ : Three experimental groups (A - C) and two control groups (pregnant and non- 
pregnant). Groups A, B and C were treated with $0.3 \mathrm{~g} / \mathrm{kg}, 0.8 \mathrm{~g} / \mathrm{kg}$ and $2 \mathrm{~g} / \mathrm{kg}$ Ethanol respectively via oral gavage, once daily for 30 days. Blood samples were collected from the female rats via retro orbital puncture and the sera obtained were used for the determination of serum Alanine transaminase (ALT) and Aspartate transaminase (AST), Alkaline phosphatase (ALP), Urea and Creatinine levels. Liver, kidney and uterus were excised after animal sacrifice for histopathological studies.

Results: A statistically significant increase in ALT, AST and ALP levels was observed only in rats treated with $0.3 \mathrm{~g} / \mathrm{kg} /$ day of ethanol when compared with the controls $(P=.000)$. Serum creatinine and urea levels in all groups showed no difference when compared with the controls. However, varying degrees of micro-architectural changes were observed in the liver, kidneys and uterus of rats in all treatment groups.

Conclusion: The present data suggest that alcohol consumption during pregnancy causes histological lesions that may be responsible for the tissue alterations observed in the experimental animals.

Keywords: Alcohol; pregnancy; histopathology; biochemical parameters.

\section{INTRODUCTION}

Alcohol (ethanol) ingestion causes various social, economic and health consequences across the world in most industrialized and also developing countries [1]. Consumption of alcoholic drinks by women is common worldwide but its use in pregnancy has become a major public health problem [2]. Several lines of evidence suggest potential harm which alcohol consumption by pregnant women can pose to the fetus which can influence the risk of developing chronic disorders later in the offspring's life [3,4]. Alcohol is a known teratogen and its exposure in utero results in alcohol-related birth defects especially Fetal Alcohol Spectrum Disorders (FASD) [5,6]. Decreased birth weight, retarded intellectual development and lowered IQ scores have also been associated with alcohol use in pregnancy [7].

In Nigeria, the consumption of alcohol plays a role in religious, political, social and economic relationships, and its consumption is common among adults of 18 years and above [8]. In Canada and the United States, alcohol use by pregnant women rates of up to $11 \%$ and $12 \%$ respectively [9]. The rates of alcohol use by African women are on the increase ranging from $1 \%$ to $30 \%$ for current use drinkers and $4 \%$ to $41 \%$ for heavy drinkers [10].

In the United States roughly one of every eight women continues to drink during her pregnancy, even despite public-awareness on alcoholic drinks [11]. Alcohol is the substance most commonly abused among pregnant women despite the fact that many complications (maternal and fetal) arising from alcohol addiction have been documented [6]. It is unfortunate that alcoholism is often neglected in pregnant patients, because the effects of alcohol addiction are often considered as having less adverse impact and more difficult to diagnose.

Although a wide variety of reports have shown that alcohol consumption in pregnancy exerts negative effects in offsprings of both human and experimental animals [12-16]. There is paucity of information and documented scientific research on the end-organ effects of alcohol during pregnancy. For this reason, the present study was conducted to assess histological structures of the liver, kidney and uterus of female rats intoxicated with ethanol during pregnancy.

\section{MATERIALS AND METHODS}

\subsection{Procurement and Reconstitution of Ethanol}

Absolute ethanol (concentration of $0.788 \mathrm{~kg} / \mathrm{l}$ ) used for the study was purchased from Sigma Aldrich Chemicals limited, USA. A dilution of $20 \%$ was prepared from the stock by adding $800 \mathrm{mls}$ of pyrogen free water to $200 \mathrm{mls}$ of ethanol. This was kept in the refrigerator at $4 \pm 2^{\circ} \mathrm{C}$ until needed.

\subsection{Animal Housing}

Twenty-eight (28) albino Wistar rats (twenty females and eight males) ( 180 - $200 \mathrm{~g})$ were obtained from Animal House of Department of Physiology, University of Nigeria Enugu Campus (UNEC). They were housed under standard condition of temperature $\left(27 \pm 2^{\circ} \mathrm{C}\right)$ with twelve- 
hour light/dark periodicity. The animals were weighed and divided into five groups (A - E) of four (4) female and two (2) male rats each, except for group $E$ which served as the nonpregnant control and had only four (4) female rats. These animals were housed in clean gauzed cages in groups and fed on standard

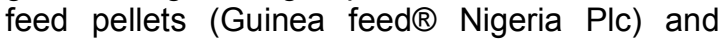
clean water ad libitum. Acclimatization was for two weeks. Animals were handled in this study in accordance with protocols approved by Institutional guidelines on Animal Care and Use Committee and conform to established guidelines set by National Institutes of Health on experiments involving the use of animals.

\subsection{Estrous Cycle Determination and Animals Impregnation}

Estrous cycle determination was conducted as previously described [17] and mating was done on sixteen female rats in groups $A-D$ at ratio of $1: 2$ [male/female rats] i.e. 2 male rats/cage. The female rats were left with the males until signs of mating were detected (presence of vaginal plug). After the period of mating, conception was achieved in most of the rats in each cage.

\subsection{Experimental Design}

Ethanol administration was commenced immediately after mating (on Day 15). Groups A, $\mathrm{B} \& \mathrm{C}$ served as the test groups and received 0.3 $\mathrm{g} / \mathrm{kg}, 0.8 \mathrm{~g} / \mathrm{kg}$ and $2 \mathrm{~g} / \mathrm{kg}$ per kilogram body weight of ethanol orally via oropharyngeal route using oral cannula for thirty (30) days. Groups D and $E$ received no treatment and hence served as the pregnant and non-pregnant controls respectively.

\subsection{Sample Collection and Biochemical Assays}

At the end of the thirtieth day, the animals were weighed and the experiment was terminated. Blood samples were collected by retro-orbital puncture of the medial canthus of the eye under anesthesia using capillary tube into plain tubes. The blood samples were centrifuged and sera were separated from each sample for biochemical analysis. Parameters assayed included Alkaline Phosphatase (ALP) and Aspartate Transaminase (AST) by colorimetric method [18]. Alanine transaminase (ALT) estimation by colorimetric method [19]. Creatinine was estimated by modified Jaffe procedure by Blass et al. [20]. Urea was estimated by modified Berthelot enzymatic method by Searcy et al. [21].

\subsection{Determination of Relative Organ Weight}

The rats were sacrificed under chloroform anaesthesia and the visceral organs of interest (namely liver, kidney and uterus) were excised. Necropsy was carried out to observe for the presence of lesions or any signs of abnormality. The liver and kidneys of each rat were blotted with filter paper and weighed on a balance. The relative organ weight [ROW] of each organ was calculated thus:

$$
\text { ROW }=\frac{\text { Absolute organ weight }(\mathrm{g})}{\text { Body weight of rat on sacrifice }(\mathrm{g})} \times 100
$$

\subsection{Tissue Processing and Microscopy}

The excised organs from the sacrificed rats were further fixed in $10 \%$ formal saline prior to histological processing using paraffin wax embedding technique for light microscopical examination. The tissues were taken through processes of dehydration, clearing and wax impregnation using an Automatic tissue processor. The wax impregnated tissues were 'blocked out'with paraffin wax prior to cutting of sections with the rotary microtome (Hertz 150, Cambridge model). The tissue sections of $5 \mu \mathrm{m}$ were produced and further stained according to the Haematoxylin and Eosin [H and E] staining technique as described by Baker et al. [22]. The sections were examined using Olympus binocular microscope with in-built lighting system.

\subsection{Statistical Analysis}

The statistical analysis was done using Statistical Package for Social Sciences (SPSS) version 20.0. Data obtained were expressed, where appropriate, as mean \pm standard error of mean (SEM). Differences between mean values were determined with one-way analysis of variance (ANOVA) followed by Tukey's post hoc tests. $p<.05$ was considered significant.

\section{RESULTS}

\subsection{Relative Organ Weights}

The results of the relative organ weights (ROW) of the liver and kidney samples from the rats in the respective study groups are shown in Fig. 1. The results of the ROW for the liver samples 
were found to be significantly higher for rats in all treatment groups when compared with the pregnant control (group D) $(p<.05)$ and only in groups $A$ and $C$ when compared with the nonpregnant control (group E) $(p<.05)$.More so, statistically significant increase in the mean ROW estimation for the kidney samples were observed in all treatment groups when compared with pregnant and non-pregnant controls.

\subsection{Biochemical Parameters}

\subsubsection{Liver marker enzyme levels}

The effects of treatment with graded doses of ethanol on serum levels of liver marker enzymes are depicted Table 1. Elevated levels of ALT, AST and ALP were observed only in rats treated with $0.3 \mathrm{~g} / \mathrm{kg}$ of ethanol (group A) when compared with the pregnant control (group D) $(p=.000<.05)$. However, in comparison with non-pregnant control, increased and decreased levels of AST and $A L T$ were observed in groups $A$ and $B$ respectively $(p=.001<.05)$.

\subsubsection{Serum creatinine and urea levels}

Results of the serum creatinine and urea levels in all treatment and control groups are also shown in Table 1. A significant decrease $(p=.001<.05)$ in mean serum urea level was observed in rats treated with $0.8 \mathrm{~g} / \mathrm{kg} \mathrm{b}$.wt. of ethanol (group B) when compared with pregnant rat control group (group D). No change was observed in values obtained from other treatment groups (group $A$ and $C$ ) in the parameters estimated.

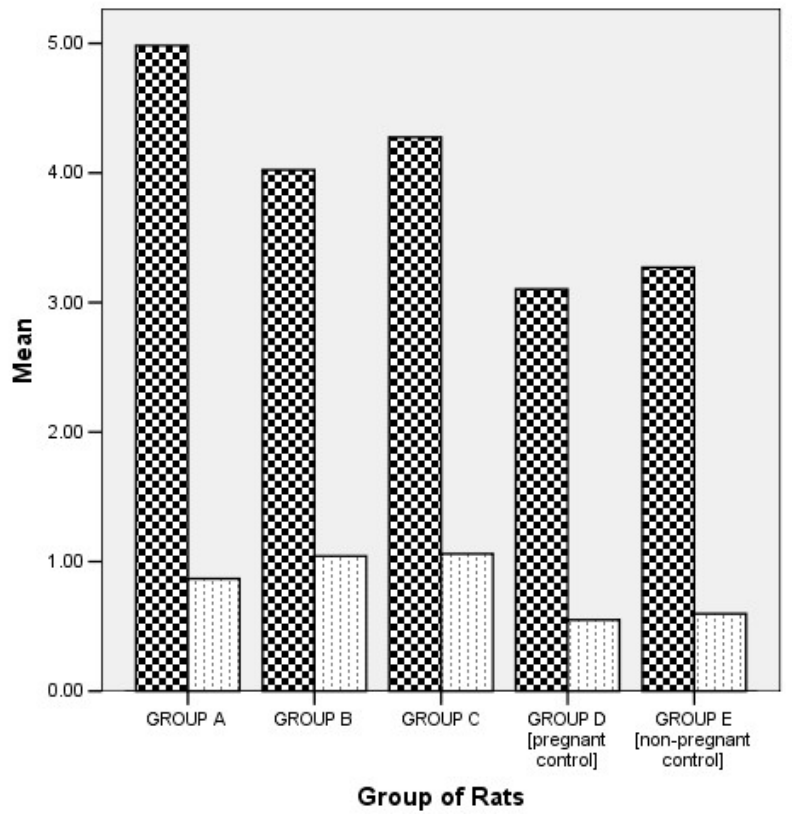

W Liver weight ( $g / 100 \mathrm{~g})$

$\square$ Kidney weight $(\mathrm{g} / 100 \mathrm{~g})$

Group of Rats

Fig. 1. Graph showing the mean organ weights [liver and kidney] [g/100 g] ethanol intoxicated rats and controls

Table 1. Comparison of levels of serum biochemical parameters of treatment groups [Ethanol - fed rats] and controls

\begin{tabular}{|c|c|c|c|c|c|}
\hline Groups & ALT [IU] & AST [IU] & ALP [IU] & $\begin{array}{l}\text { Creatinine } \\
\text { (mg/dl) }\end{array}$ & $\begin{array}{l}\text { Urea } \\
\text { (mg/dl) }\end{array}$ \\
\hline $\mathrm{A}[0.3 \mathrm{~g} / \mathrm{kg}$ of $\mathrm{Et}]$ & $74.75 \pm 2.75^{*}$ & $65.50 \pm 0.96^{\star \#}$ & $85.75 \pm 17.11$ & $0.83 \pm 0.05$ & $36.25 \pm 3.15$ \\
\hline $\mathrm{B}[0.8 \mathrm{~g} / \mathrm{kg}$ of $\mathrm{Et}]$ & $49.00 \pm 3.51^{\#}$ & $52.00 \pm 3.03$ & $41.50 \pm 7.08$ & $0.80 \pm 0.04$ & $26.75 \pm 2.84^{*}$ \\
\hline $\mathrm{C}[2 \mathrm{~g} / \mathrm{kg}$ of $\mathrm{Et}]$ & $59.00 \pm 7.42$ & $54.00 \pm 3.39$ & $63.00 \pm 12.19$ & $0.83 \pm 0.09$ & $30.00 \pm 1.91$ \\
\hline $\mathrm{D}[\mathrm{PC}]$ & $53.75 \pm 2.39$ & $47.75 \pm 0.85$ & $43.00 \pm 15.23$ & $0.83 \pm 0.09$ & $35.00 \pm 2.48$ \\
\hline $\mathrm{E}[\mathrm{NPC}]$ & $63.50 \pm 2.96$ & $53.50 \pm 1.85$ & $76.25 \pm 6.10$ & $0.85 \pm 0.10$ & $30.75 \pm 0.95$ \\
\hline
\end{tabular}




\subsection{Histological Findings}

\subsubsection{Liver}

The photomicrographs of the hepatic lobule of control rats (Pregnant and non-pregnant) revealed normal features. The pericentral region of the hepatic lobule showed preserved cytoplasmic architecture with hexagonal lobules consisting of central vein and radially arranged hepatocytes. The sinusoidal spaces which are lined by endothelial cells are intact. The hepatic portal veins, bile ducts and hepatic artery within the portal tract found at the periphery of the hepatic lobule are evident [Fig. 2A]. The liver sections from ethanol treated rats showed dosedependent degree of lesions on the hepatic
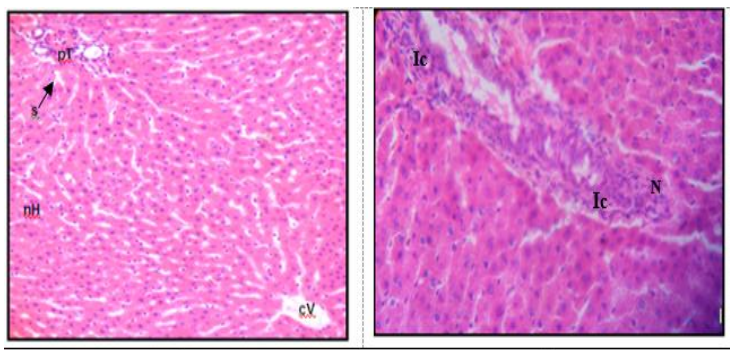

tissue. Necrotic hepatocytes, inflammatory cellular infiltration, vacuolation, widened sinusoidal spaces and presence of binucleate cells are evident (Fig. 2B - D).

\subsubsection{Kidney}

The histological observations of the cortical and medullary sections of the renal tissue of the control rats showed normal histoarchitectural features: normal glomeruli, tubules and blood vessels (Fig. 3A). Kidney sections from rat treated with ethanol revealed some degrees of histological changes viz: extrusion of some glomeruli, engorged glomeruli, eroded tubules, and inflammatory cellular infiltration (Fig. 3B - D).

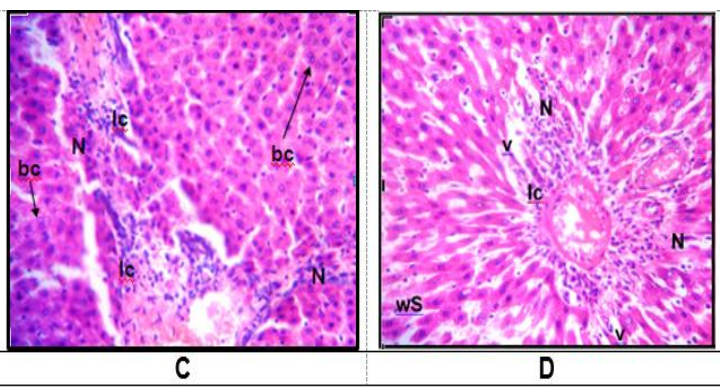

Fig. 2. Photomicrographs of liver sections of rats

[Stain: Haematoxylin \& Eosin]; (A) Normal control group [Mag.x100]: Liver section shows normal histoarchitecture; normal hepatocytes $(\mathrm{nH})$ with central nucleus, portal tract $(\mathrm{pT})$, radially distributed sinusoidal spaces and central vein (cV) are shown. (B) $0.3 \mathrm{~g} / \mathrm{kg}$ b.wt of Ethanol - treated group [Mag.x400]: showing mild necrosis and inflammatory cellular infiltration (IC). (C) $0.8 \mathrm{~g} / \mathrm{kg} \mathrm{b.wt} \mathrm{of} \mathrm{Ethanol} \mathrm{-} \mathrm{treated} \mathrm{group} \mathrm{[Mag.x} \mathrm{400]:} \mathrm{The}$

tissue parenchyma shows evidence of necrosis (n), inflammatory cellular infiltration (Ic) and presence of binucleate cells (bc). (D) $2 \mathrm{~g} / \mathrm{kg}$ b.wt of Ethanol - treated group [Mag.x400]: liver histoarchitecture shows disassociation of hepatic tissues with resultant widening of the sinusoidal spaces (WS), necrosis (N) and inflammatory cellular infiltration (IC)

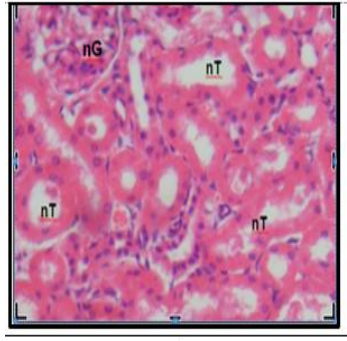

A

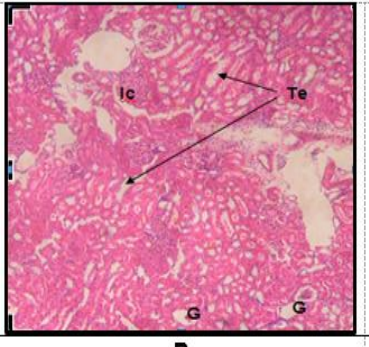

B

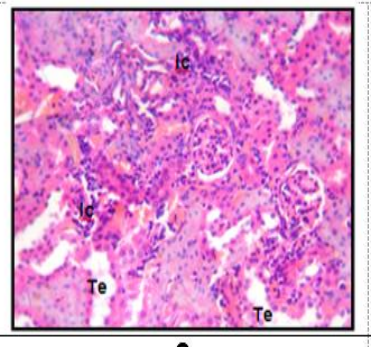

C

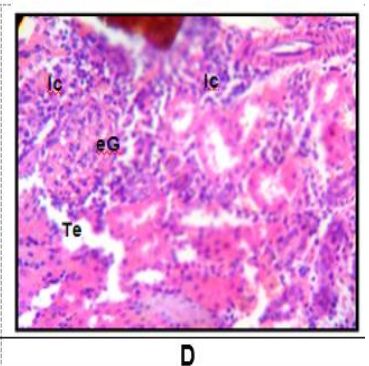

Fig. 3. Photomicrographs of kidney sections of rats

[Stain: Haematoxylin \& Eosin]; (A) Normal control group [Mag.x100]: Kidney cortex section shows normal histoarchitecture; normal glomerulus ( $n G)$ and normal tubules (nT) are observed (B) $0.3 \mathrm{~g} / \mathrm{kg}$ b.wt of Ethanol treated group [Mag.x400]: showing glomerular extrusion (G), tubular erosion (Te) and infiltration of inflammatory cells (IC). (C) $0.8 \mathrm{~g} / \mathrm{kg} \mathrm{b.wt} \mathrm{of} \mathrm{Ethanol} \mathrm{-} \mathrm{treated} \mathrm{group} \mathrm{[Mag.x400]:} \mathrm{features} \mathrm{observed} \mathrm{are} \mathrm{tubular} \mathrm{erosion} \mathrm{\&}$ degeneration (Te) and inflammatory cellular infiltration (IC). (D) $2 \mathrm{~g} / \mathrm{kg} \mathrm{b.wt} \mathrm{of} \mathrm{Ethanol} \mathrm{-} \mathrm{treated} \mathrm{group} \mathrm{[Mag.x400]:}$ the cortex of the kidney shows engorged glomeruli (eG) with adherence on the Bowman's capsule, tubular erosion and degeneration (Te) and infiltration of inflammatory cells (IC) 

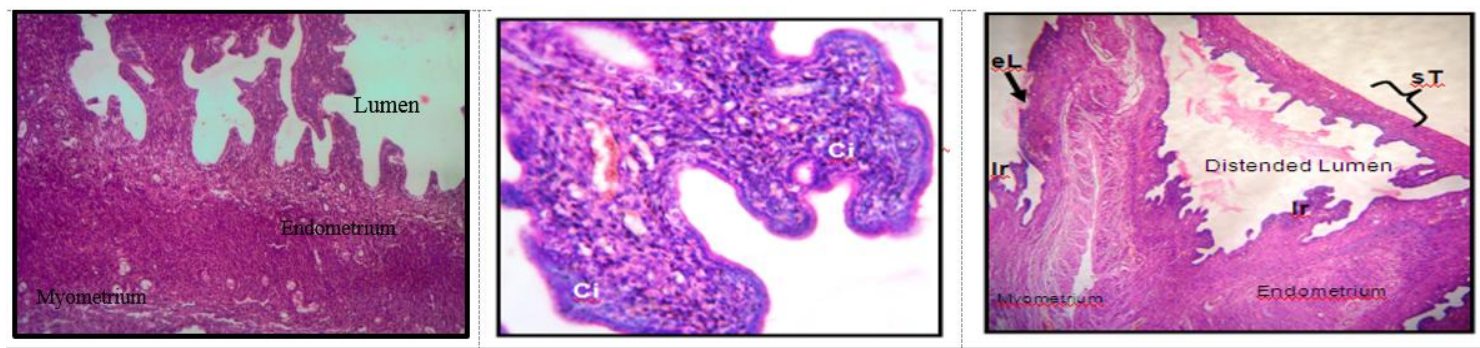

$\mathbf{A}$

B

Fig. 4. Photomicrographs of uterus sections of rats

[Stain: Haematoxylin \& Eosin]; (A) Normal control group [Mag.x100]: Uterus section shows normal histoarchitecture; normal endometrium (bearing numerous glands) and normal myometrium. (B) $0.8 \mathrm{~g} / \mathrm{kg} \mathrm{b.wt} \mathrm{of}$ Ethanol - treated group [Mag.x400]: Showing marked cellular infiltration in the endometrium (Ci) (C) $2 \mathrm{~g} / \mathrm{kg}$ b.wt of Ethanol - treated group [Mag.x40]: Uterine lumen is slightly distended; shortened thickness of uterine wall \{sT\}; irregular epithelial folding $\{I r\}$ with loss of epithelial lining $\{e L\}$, fewer endometrial glands are seen

\subsubsection{Uterus}

The uterine histology of control rats showed normal features: single layered columnar epithelial cell with elongated nuclei at the base of the cells, numerous irregular and tortuous endometrial glands, highly folded epithelial lining and endometrial stroma (Fig. 4A). The uterine tissue of ethanol treated pregnant rats revealed some degree of cellular infiltration in the endometrium, slightly distended uterine lumen, shortened thickness of the uterine walls, irregular epithelial folding with loss of epithelial lining and presence of fewer endometrial glands (Fig. 4B and $\mathrm{C}$ ). The photomicrographs obtained from the control and treated sections of the organs studied are shown below.

\section{DISCUSSION}

Alcohol use disorders are significant clinical problems due to the devastating high prevalence and health impacts across the globe $[23,24]$. This study investigated changes in some blood profiles and end-organ effects of alcohol in pregnancy. The histopathological findings on the liver of the treated pregnant rats showed that ethanol consumption may lead to liver damage. Previous researchers have reported that one of the organs that most commonly exhibit deleterious changes due to alcohol consumption is the liver [25]. In alcoholics, end products of alcohol metabolism cause many of the changes in liver function and structure [26,27]. Alcohol breakdown results in the generation of acetaldehyde, a highly reactive and toxic molecule which reacts with most of the cell components, changing their structures and functions, or by contributing to other mechanisms that would eventually encourage enhanced oxidative damage $[25,28,29]$.

Acetaldehyde may induce liver injury by interfering with extracellular matrix production or by involving the immune system [29-31]. The inflammatory cellular infiltrates and enlargement of sinusoidal cells support that the immune system was activated. Immune cells are activated in response to an injurious impact [32]. Recognition of the formed adducts by the immune system as a result of alcohol consumption may trigger harmful immune responses that could lead to liver damage $[29,33]$.

Measurements of serum Alanine Transaminase (ALT) and Aspartate Transaminase (AST) are widely used as markers in evaluating the degree of their injury $[34,35]$, ALT being a more specific enzyme for liver dysfunction. Increased levels of the liver enzymes were only observed to be statistically significant in rats treated with the low dose of ethanol $(0.3 \mathrm{~g} / \mathrm{kg} / \mathrm{day})$ after the 30-day treatment. However, no discernible effect was observed in the liver enzyme levels of the mother rats treated with $0.8 \mathrm{~g} / \mathrm{kg}$ and $2 \mathrm{~g} / \mathrm{kg} / \mathrm{day}$ of ethanol when compared with the controls even though the liver microanatomical features of all the treated rats in all groups suggest deleterious changes. Perhaps, the liver enzyme levels of moderate and high dose groups may have returned to normal by the end of the experiment when the analysis was conducted. Unfortunately, in this study, the possible effects of ethanol intoxication on the liver markers on weekly basis could not be performed so as to provide a distinct picture on the observed findings. It is possible that the higher quantities of ethanol may have 
exerted deleterious effects on the hepatocytes earlier in the treatment period and this impact may have resulted to increased serum levels of the marker enzymes. Previous researchers have shown markedly increased levels of ALT and AST after only five days of ethanol intoxication [36]. In light of the present evidence indicating that normal values of serum liver marker enzymes are observed after a sub-chronic intoxication with ethanol warrants further studies.

It is rather surprising at the extent of damage on the liver tissue parenchyma at the doses administered in the present study. The severity of the lesions increased with increasing concentration. Ishak et al. [37], reported that in early development of alcoholic liver disease, necrotic cell death is predominantly observed in the pericentral region of the hepatic lobule. The hepatocyte losses its capacity to repair damage induced by the continuous alcohol exposure. This may be the reason for reduced number of binucleate cells in liver tissues of rats treated with the higher doses in this study when compared with the liver of rats treated with 0.3 $\mathrm{g} / \mathrm{kg} / \mathrm{day}$ of ethanol. Presence of binucleate cells in the liver tissue suggests regeneration of the hepatic tissue in compensation for the tissue damage. However, the process of repair and replacement of cellular macromolecules are energy-requiring processes that can only proceed if there is a sufficiency of Adenosine triphosphate (ATP) [38]. ATP synthesis becomes compromised when damage of the liver mitochondria occurs due to alcohol consumption [39]. Previous studies have emphasized on the role of ATP in the maintenance of hepatocyte viability in an environment where the tissue is being subjected to ethanol-associated toxicity $[40,41]$.

The kidney histological examination revealed degeneration of kidney tubules with inflammatory cellular infiltration at peritubular, glomerular and vascular regions. Few glomerular enlargements due to hydropic change may be the explanation for the increase kidney organ weight $(\mathrm{g} / 100 \mathrm{~g}$ of body weight] in the treated groups when compared with the controls. However, the results of the kidney function tests [serum creatinine and urea levels] did not show obvious changes to connote kidney damage.

Chung et al. [42] documented a similar nonsignificant difference in serum creatinine and blood urea nitrogen levels while comparing nonalcohol users, alcohol users and ex-users.
However, they discovered that subjects with chronic alcohol consumption have significantly higher estimated glomerular filtration rate and Creatinine clearance rate $(\mathrm{Ccr})$ values than nondrinkers. Although the kidney function parameters in the present study did not show any discernible effects, the microscopical examination of the renal tissue showed obvious histopathological features consistent with renal damage.

The histo-architecture of the uterus of ethanol fed mother rats after pregnancy showed some tissue damage between the treatment groups. Increased cellular infiltration by polymorphs, congested vessels and marked changes in the epithelial linings were observed. Such findings when severe may lead to oedema which may induce unfavourable bed of endometrium for implantation and embryo implantation may fail [43]. Reduced litter sizes of rodents have been documented in previous reports as a result of alcohol consumption during pregnancy [44].

\section{CONCLUSION}

In conclusion, our data indicated a preliminary evidence that moderate ( $<2 \mathrm{~g}$ drinks/day) and heavy (>2 g drinks/day) alcohol consumption during pregnancy increases risk of tissue damage in rats.

\section{DISCLAIMER}

The products used for this research are commonly and predominantly use products in our area of research and country. There is absolutely no conflict of interest between the authors and producers of the products because we do not intend to use these products as an avenue for any litigation but for the advancement of knowledge. Also, the research was not funded by the producing company rather it was funded by personal efforts of the authors.

\section{ETHICAL APPROVAL}

Ethical approval for this study was obtained from the ethical committee Faculty of Veterinary Medicine, University of Nigeria Nsukka, Enugu State. All authors hereby declare that the experiments have been examined and approved by the appropriate ethics committee and have therefore been performed in accordance with the ethical standards laid down in NIH publication No. 85-23, revised 1985. 


\section{ACKNOWLEDGEMENT}

The authors express their deep sense of gratitude to all the staff of the Animal house, College of Medicine, University of Nigeria Enugu Campus.

\section{COMPETING INTERESTS}

Authors have declared that no competing interests exist.

\section{REFERENCES}

1. Nayanatara AK, Nagaraja HS, Ramaswamy C, Bhagy alaksgmi K, Bhat MR, Harini N. Estimation of tissue liquid peroxidation level and organ weight in lifters of waster rats exposed to prenatal alcohol. JFBS. 2009;(2):44-47.

2. Charya G, Bhuvaneswar MD, Grance Change MD, Theodore A. Sterm MD. Alcohol use in pregnancy: Prevalence and Impact, J Clin Psychiat. 2007;9(6):455459.

3. Vickers $\mathrm{MH}$, Breier $\mathrm{BH}$, McCarthy $\mathrm{D}$, Gluckman PD. Sedentary behavior during postnatal life is determined by the prenatal environment and exacerbated by postnatal hypercaloric nutrition. Am J Physiol Regul Integr Comp Physiol. 2003;285:271-273.

Available:https://doi.org/10.1152/ajpregu.0 0051.2003

4. Rebecca M, Reynolds Keith M, Godfrey Mary Barker, Clive Osmond, David I, Phillips W. Stress responsiveness in adult life: Influence of mother's diet in late pregnancy. The J Clin Endocrin Metab. 2007;92(6):22082210.

Available: https://doi.org/10.1210/jc.20070071

5. Roebuck TM, Mattson SN, Riley EP. A review of the neuroanatomical findings in children with Fetal Alcohol Syndrome or prenatal exposure to alcohol. Alcohol: Clin Expr Res. 1998;22:339-344.

Available:https://doi.org/10.1111/j.15300277.1998.tb03658.x

6. Ornoy A, Ergaz Z. Alcohol abuse in pregnant women: Effects on the fetus and newborn, mode of action and maternal treatment. Int J Envir Res Pub Health. 2010;7(2):364-379.

Available:https://doi.org/10.3390/ijerph702 0364
7. DePetrillo P, McDonough M. Major pathologies associated with acute and chronic alcohol use: A reference summary. The Alcohol Withdrawal Treatment Manual. 2007;1-17.

8. Oshodin OG. International handbook on alcohol and culture. Greenwood Press, Westport, CT. Nigeria: in Database Heath ed. 1995;213-223.

9. Statgerstrom J, Chan G, Nelsen P. Predictors of drinking during pregnancy: A systematic review. J Womens' Health. 2011;20(6):901-903.

Available:https://doi.org/10.1089/jwh.2010. 2216

10. Martinez P, Roislien J, Naidoo N, Clausen $\mathrm{T}$. Alcohol abstinence and drinking among African women: data from the World Health Surveys. BMC Pub Health. 2011;11:160. Available:https://doi.org/10.1186/14712458-11-160

11. Bakhireva LN, Savage DD. FOCUS ON. Biomarkers of fetal alcohol exposure and fetal alcohol effects. Alcohol Res Health. 2011;34(1):56-63.

12. Jones $\mathrm{KL}$, Smith DW. Recognition of the fetal alcohol syndrome in early infancy. Lancet.1973;2:999-1001.

Avasilable:https://doi.org/10.1016/S01406736(73)91092-1

13. Jacobson JL, Jacobson SW, Sokol RJ, Martier SS, Ager JW, Kaplan Estruo MG. Teratogenic effects of alcohol on infant development. Alcohol Clin. Exp. Res. 1993;17:174-183.

Available:https://doi.org/10.1111/j.1530-

0277.1993.tb00744.x

14. Sampson PD, Streisgut AP, Bookstein FL, Ookstein $F$, Little RE, Clarrens SK. Incidence of fetal alcohol syndrome and prevalence of alcohol - related neurodevelopmental disorder. Teratolo. 1997;56: 317-326.

Available:https://doi.org/10.1002/(SICI)109 6-9926(199711)56:5<317::AID-

TERA5>3.0.CO;2-U

15. Day NL, Leech, SL, Richardson GA, Cornelius MD, Robles $\mathrm{N}$, Larkby C. Prenatal alcohol exposure predicts continued deficits in offspring size at 14 years of age. Alcoholism: Clin Exp Res. 2002;26(10):1584-1591.

Available:https://doi.org/10.1111/j.15300277.2002.tb02459.x

16. Wattendorf DJ, Muenke M. Fetal alcohol spectrum disorders. An Fam Physician 2005;72:279-282,285. 
17. Marcondes FK, Bianchi FJ, Tanno AP. Determination of the estrous cycle phases of rats: some helpful considerations. Braz J Biol. 2001;62(4A):609-614.

Available:https://doi.org/10.1590/S151969842002000400008

18. Reitman S, Frankel S. A colorimetric method for the determination of serum glutamic oxaloacetic acid and ghitamin pyruvic acid transamin ases. Am J Clin patholo.1957;1:56-63.

Available:https://doi.org/10.1093/ajcp/28.1. 56

19. Roy AV. Enzymes in clinical chemistry. J clin chem. 1970;16:431-439.

Available:https://doi.org/10.1093/clinchem/ 16.5.431

20. Blass KG, Thibert RJ, Lam LK. Modified jaffe procedure for serum creatinine. Clin Bioch. 1974;12:18-21.

Available:https://doi.org/10.1515/cclm.197 4.12.7.336

21. Searcy RL, Reardon JE, Foreman JA. Estimation of enzymatic urea. Am J Med Tech. 1967;33:15-20.

22. Baker FJ, Silverton RE. Introduction to medical laboratory technology. London: Butterworth and co Publishers Ltd; 1966.

23. Rhem J. Alcohol related morbidity and mortality. Alcoh Res Health. 2003;27(1): 39-51.

24. Connor JP, Haber PS, Hall WD. Alcohol use disorders. The Lancet. 2016; 387(10022):988-998.

Available:https://doi.org/10.1016/S01406736(15)00122-1

25. Mukherjee S. Alcohol metabolism and generation of free radicals: A deep insight. OA Alcohol. 2014;2(1):10.

Available:https://doi.org/10.13172/20530285-1-2-774

26. Lieber CS. Metabolic effects of acetaldehyde. Biochem Society Transac. 1988;16:241-247.

Available:https://doi.org/10.1042/bst01602 41

27. Tumar DJ, Sorrell MF. The role of acetaldehyde adducts in liver injury. In: Hall P. ed. Alcoholic Liver Disease: Pathology and Pathogenesis London: Edward Arnold. 1995;89-99.

28. Lieber CS. Alcohol: Its metabolism and interaction with nutrients. Annu Rev Nutr. 2000;20(1):395-430.

Available:https://doi.org/10.1146/annurev.n utr.20.1.395
29. Tuma DJ, Casey CA. Dangerous byproducts of alcohol breakdown: Focus on adducts. Alcoh Res Health. 2003;27: 285-290.

30. Niemela O, Parkkila S, Juvonen RO, Vitala K, Gelboin HV, Pasanen M. Cytochromes P450 2A6, 2El and 3A production of protein aldehyde adducts in the liver of patients with alcoholic and non alcoholic liver diseases. J Hepatol. 2001;33:893901.

Available:https://doi.org/10.1016/S01688278(00)80120-8

31. Worrall S, Thiele GM. Protein modification in ethanol toxicity. Adver Drug Reactions Toxicolo Rev. 2001;20:133-159.

32. El-Banawy MA, Sana SM, Sakr SA, ElElaimy IA, Mahran HA. Histopathological studies on the effect of anticoagulant rodarcide "Brodifacoum" on the liver of rat. J Egy Ger. Soc. Zol. 1993;12(3):185-227.

33. Yokoyama A, Muramatsu T, Omori T, Matsushita S, Yoshimizu $\mathrm{H}$, Higuchi $S$, Yokoyama T, Maruyama K, Ishii H. Alcohol and aldehyde dehydrogenase gene polymorphisms influence susceptibility to esophageal cancer in Japanese alcoholics. Alcoholism: Clin Exp Res. 1999;23(11): 1705-1710.

Available:https://doi.org/10.1111/j.15300277.1999.tb04064.x

34. Dunn W, Angulo P, Sanderson S, Jamil LH, Stadheim L, Rosen C, et al. Utility of a new model to diagnose an alcohol basis for steatohepatitis, Gastroenterol. 2006; 131:1057-1063.

Available:https://doi.org/10.1053/j.gastro.2 006.08.020

35. Conigrare KM, Daries $P$, Haber $P$, Whitefield JB. Traditional markers of excessive alcohol use. Addition 98. 2003; 2:31-43.

Available:https://doi.org/10.1046/j.13596357.2003.00581.x

36. Lee SJ, Kim SY, Min H. Effects of vitamin $C$ and $E$ supplementation on oxidative stress and liver toxicity in rats fed a low-fat ethanol diet. Nutr Res Prac. 2013;7(2):109 -114 .

Available:https://doi.org/10.4162/nrp.2013. 7.2.109

37. Ishak KG, Zummerman $\mathrm{HJ}$, Ray MB. Alcoholic liver disease: Pathologic, pathogenetic and clinical aspects. Alcoholism: Clin Exp Res. 1991;15:45-66. Available:https://doi.org/10.1111/j.15300277.1991.tb00518.x 
38. Bridges JW, Benford DJ, Hubbard SA. Mechanisms of toxic injury. Ann NY Acad Sci. 1983;407(1):42-63.

Available:https://doi.org/10.1111/j.17496632.1983.tb47813.x

39. Hoek JB. Mitochondrial energy metabolism in chronic alcoholism. Current Topics in Bioenergetics. 1994;17:197-241.

Available:https://doi.org/10.1016/B978-012-152517-0.50012-8

40. Bailey SM, Cunningham CC. Acute and Chronic ethanol increases reactive oxygen species generation and decreases viability in fresh, isolated rat hepatocytes. Hepatol. 1998;28:1318-1326.

Available:https://doi.org/10.1002/hep.5102 80521

41. Young TA, Bailey SM, Van Horn CG, Carol $C$, Cunningham C. Chronic ethanol consumption decreases mitochondrial and glycolytic production of ATP in Liver, Alcohol \& Alcoholism. 2006;41(3):254-260.
Available:https://doi.org/10.1093/alcalc/agl 017

42. Chung FM, Yang YH, Shieh TY, Shin SJ, Tsai JC, Lee YJ. Effect of alcohol consumption on estimated glomerular filtration rate and creatinine clearance rate. Nephrolo Dial Transplantat. 2005; 20(8):1610-1616.

Available:https://doi.org/10.1093/ndt/gfh84 2

43. Dehghan $\mathrm{M}$, Jafarpour $\mathrm{M}$, Mahmoudian A. The effect of morphine administration on structure and ultrastructure of uterus in pregnant mice. Int J Reprod Biomed. 2010; 8(3):111-118.

44. Guerri C, Pascual M. Effects of alcohol on embryo/fetal development. In reproductive and developmental toxicology (Second edition). 2017;431-445.

Available:https://doi.org/10.1016/B978-012-804239-7.00024-X

(c) 2020 Onyemelukwe et al.; This is an Open Access article distributed under the terms of the Creative Commons Attribution License (http://creativecommons.org/licenses/by/4.0), which permits unrestricted use, distribution, and reproduction in any medium, provided the original work is properly cited.

Peer-review history:

The peer review history for this paper can be accessed here: http://www. sdiarticle4.com/review-history/54940 